\title{
Valorization of sugarcane bagasse waste for fly ash production and application as an adsorbent
}

\author{
Taimoor Khan ${ }^{a}$, Muhammad Amin ${ }^{\mathrm{a}^{*}, \text { Syed Kamran Sami }}{ }^{a}$, Muhammad Najam Khan $^{\text {a }}$, Syed Zameer \\ Ul Hassan ${ }^{b}$, Syed Haseeb Sultan ${ }^{a}$, Ali Asghar ${ }^{b}$, Anila Alic, Muhammad Qasim Khan ${ }^{d}$, Muhamamd \\ Junaid $^{e}$ \\ ${ }^{a}$ Department of Chemical Engineering, Balochistan University of Information Technology, Engineering and \\ Management Sciences (BUITEMS), 87300 Quetta, Pakistan \\ b Department of Textile Engineering, Balochistan University of Information Technology, Engineering and \\ Management Sciences (BUITEMS), 87300 Quetta, Pakistan \\ ${ }^{\mathrm{c}}$ Department of Environmental Sciences, Balochistan University of Information Technology, Engineering and \\ Management Sciences (BUITEMS), 87300 Quetta, Pakistan \\ d Sungkyunkwan University, Republic of Korea \\ ${ }^{\mathrm{e}}$ Department of Information Technology, University of Haripur, Haripur, Pakistan \\ *Corresponding author's email: engr_amin63@yahoo.com
}

\begin{abstract}
In this study, fly ash (FA) was derived from extracted sugarcane bagasse solid waste (ESBSW) and chemically modified to apply as an adsorbent. Impact of activated FA particles $(200$ and $250 \mu \mathrm{m})$ and adsorbent bed height $(4,6$ and $8 \mathrm{~mm})$ on pollutant removal efficiency was evaluated. ESBSW was combusted in laboratory-scale gasifier operated at $1000{ }^{\circ} \mathrm{C}$ for $1 \mathrm{~h}$. The black solid residue was sieved to obtain the desired particle size followed by activation with $10 \%$ and $15 \%$ sulfuric acid. Wastewater samples collected from the drainage site of BUITEMS were analyzed and treated with the prepared adsorbent. ESBSW-FA 250 activated with $15 \% \mathrm{H}_{2} \mathrm{SO}_{4}$ with 8 mm bed height showed high efficiency. Where, 94.37\%, 95.1\% and 63.5\% removal efficiency of chemical oxygen demand (COD), total solids (TS) and turbidity was attained, respectively. The pH of treated water was neutral. ESBSW has shown great potential to be used as a precursor for valuable byproducts. It's recycling for adsorbent preparation will economically and environmentally benefit the sugar industry.
\end{abstract}

Keywords- Sugarcane bagasse waste; Combustion; Fly ash; Adsorbent; Waste management; Wastewater treatment

Date Received: $10-07-2020$

Date Accepted: $12-10-2020$

Date Published: $18-12-2020$

\section{INTRODUCTION}

Water pollution caused due to hazardous substances entails a high degree of damage to the ecosystem [1]. High living standards, increased population and rapid industrialization are equally involved in the reduction and polluting the water resources. Direct drainage of domestic and industrial waste effluents on the earth surface affects the quality of surface and groundwater resources [2]. Moreover, the demand for fresh or cleaned water is increasing day by day to perform daily life activities. To overcome this challenge, waste effluent streams must be treated by suitable technique before their discharging and can be recycled for a variety of applications i.e. gardening [3].

Wastewater can be treated by different techniques such as filtration, coagulation, precipitation, adsorption, membrane filtration, ion exchange and floatation. However, the selection of suitable treatment technique is highly important concerning hazard effects of pollutants [1]. Filtration is the simplest process of treating the wastewater by passing through the bed of sand and gravels. However, the performance efficiency for the removal of pollutant is very less [4]. Other techniques such as membrane and ion-exchange are very expansive. Adsorption is low cost and very effective process. Where polluted stream came into contact with the adsorbent. The economy and performance of the adsorption process depend on the cost of adsorbent material, preparation technique and characteristics [5]. However, single Physico-chemical treatment technique is not capable of removing the pollutants up to $80 \%$ of the influent COD, TSS and color simultaneously. Combination of filtration and adsorption beds column system gave the highest removal of organics (81\%) and turbidity (94.5\%) [4].

Gravel and sand of different mesh sizes are generally applied as filtration media. In recent years, char has gained increased interest as an adsorbent due to its low cost as compared to activated carbon [3]. Fly ash produced along char is separated and have profound application as a supporting agent for concrete materials and as an adsorbent [6]. Char and fly ash are produced as a byproduct during the thermal conversion of coal, lignocellulosic or algal biomass. Their properties may differ owing to the material characteristics, pretreatment and thermal process conditions [7]. Generally, fly ash is composed of $\mathrm{SiO}_{2}$, which plays a catalytic role to adsorb the pollutants [8]. Pollutant uptake capacity of fly ash can be enhanced by modifying its surface with acid treatment.

Pakistan is an agro-industrial country and $5^{\text {th }}$ largest producer of sugarcane in the world [9]. Despite its use as a sugar precursor, it is also used for juice extraction countrywide. After processing for sugar or juice extracted sugarcane bagasse is regarded as solid waste. Obviously, at large scale processing, a 
huge quantity of this solid waste will be generated and needs to be managed. Although, its application in the paper manufacturing process has been already warranted it could also be processed for recovery of other valuable byproducts i.e. biofuel, char and fly ash. In recent years, biochar from sugarcane bagasse has been prepared and assessed for its potential as an adsorbent [10]. However, information on FA use as an adsorbent in a single-column hybrid system (filtrationadsorption) is still limited. Therefore, this work aims to (1) prepare FA of 200 and $250 \mu \mathrm{m}$ from ESBSW (2) activate by using $10 \%$ and $15 \% \mathrm{H}_{2} \mathrm{SO}_{4}$ (3) asses the performance of $\mathrm{FA}$ for COD, TS, pH and turbidity removal in the hybrid system.

\begin{tabular}{|c|} 
Waste bagasse collection and pretreatment \\
Oven drying at $105^{\circ} \mathrm{C}$ for $24 \mathrm{~h}$ \\
\hline Gasification \\
Waste bagasse gasification at $100{ }^{\circ} \mathrm{C}$ \\
\hline Fly ash was separated and sieved to obtain average \\
particle size of 200 and $250 \mu \mathrm{m}$
\end{tabular}

Figure 1. Overall processing scheme of study

\section{MATERIALS AND METHOD}

\section{A. Feedstock and chemicals}

ESBSW was collected from the local market of Quetta city and washed thrice to remove the dust particles. It was then sundried for three days until constant weight achieved. Wastewater was collected from the main drainage site of BUITEMS located near the sports complex. Sulfuric acid and distilled water were purchased from United Traders, Quetta.

\section{B. Fly ash production and activation}

Dried ESBSW was combusted in laboratory-scale updraft gasifier operated at $1000^{\circ} \mathrm{C}$ for $1 \mathrm{~h}$, as shown in Figure 2 (stage 1). The black solid residue obtained after combustion was collected and screened to separate FA. Then, FA was sieved to obtain the average particle size of 200 and $250 \mu \mathrm{m}$ and was chemically activated by soaking with $10 \%$ and $15 \%$ concentrated $\mathrm{H}_{2} \mathrm{SO}_{4}$ solution. The slurry was oven-dried at 105 ${ }^{\circ} \mathrm{C}$ for $24 \mathrm{~h}$. Dried samples were calcined in the furnace at 900 ${ }^{\circ} \mathrm{C}$ for $3 \mathrm{~h}$. Activated samples were taken out from the furnace, cooled and stored at ambient condition. The samples were named as ESBSW-FA 200 and ESBSW-FA 250.

\section{Characterization and analytical techniques}

Proximate analysis of ESBSW for moisture, ash, volatile matters and ash was performed according to as described by Amin et al. (2019) [6][11]. COD, TS, turbidity and pH of wastewater samples before and after adsorption was determined by ASTM D1252, D4906, D1889 and D1293 method, respectively. Generally, the lignocellulosic materials are less in ash as compared to third-generation resources. During combustion, the mass loss occurred at low temperature is associated with dehydration. However, above $600{ }^{\circ} \mathrm{C}$, the minerals present in the biomass tends to decompose resulting in ash formation. $\mathrm{SiO}_{2}$ is one of the major component generally found in the ash and play a catalytic role for pollutant uptake during adsorption.

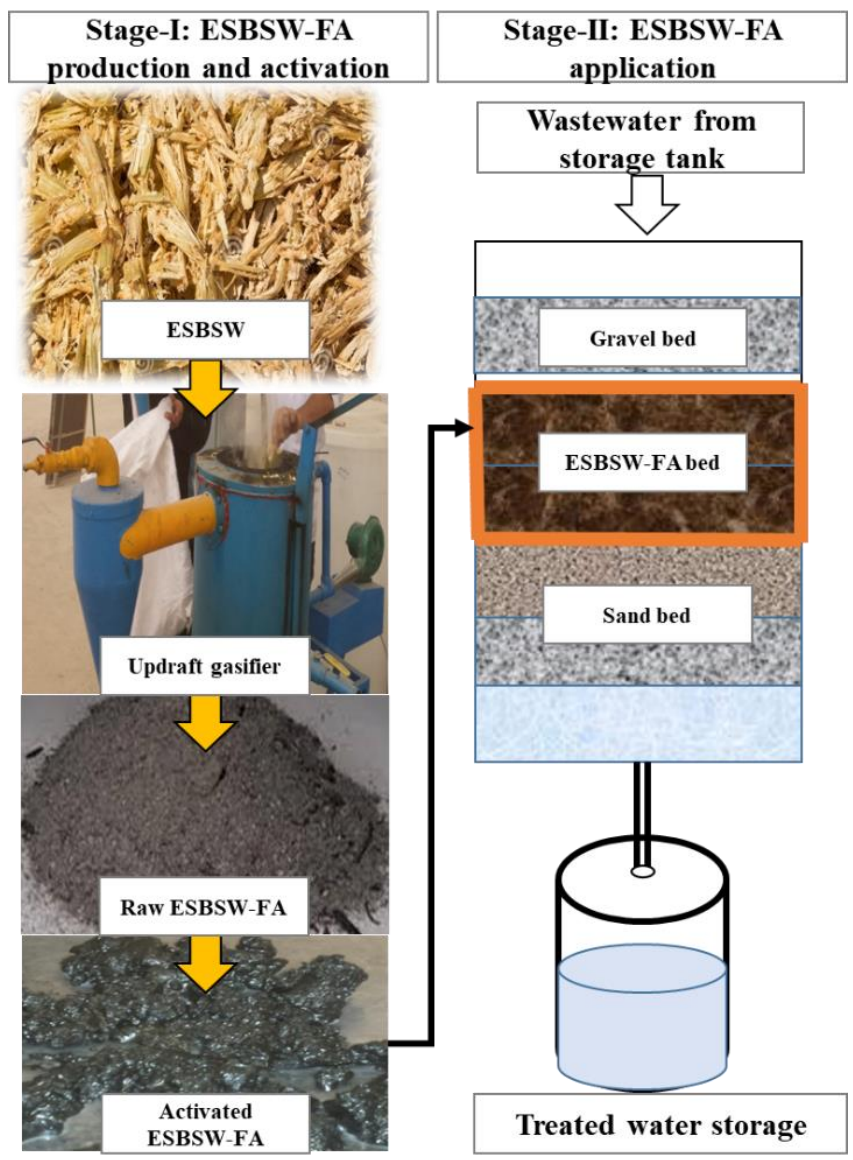

Figure 2. Overall processing scheme of study

\section{Experimental procedure: Wastewater treatment}

The adsorption bed comprised of gravel (8 mesh no.), ESBSWFA (4, 6 or $8 \mathrm{~mm})$, sand and gravel (12 mesh no.) was structured in sedimentation tank as shown in Figure 2. Height of gravels and sand bed was constant and maintained at $5 \mathrm{~mm}$. While, acid-activated ESBSW-FA bed height was varied as 4, 6 and 8 $\mathrm{mm}$. Water permeable cloth sheet was placed at the bottom surface of the tank (below sand bed). Initially, the experiments were performed at the adsorbent bed height of $4 \mathrm{~mm}$. Wastewater from storage tank was pumped to the adsorption 
tank at a controlled pressure. The pressure and flow limit was assessed in preliminary runs. Treated water was collected in the storage tank. Similarly, the rest of the experiments were performed at 6 and $8 \mathrm{~mm}$ adsorbent bed height. Treated water samples were analyzed and removal efficiency was calculated.

\section{RESULTS AND DISCUSSION}

\section{A. ESBSW proximate analysis and FA yield}

The moisture in dried ESBSW was found below $9 \%$. Biomass with moisture less than $10 \%$ is regarded as a good quality product owing to ease in handling [12]. Volatile matters, fixed carbon and ash were found $68.3 \%, 20.2 \%$ and $2.5 \%$, respectively in ESBSW. It has been reported that generally, bagasse consists of fibres (48\%), water $(50 \%)$ and soluble solids such as sugars (2\%) [13]. Bagasse is an important lignocellulosic material containing cellulose $42 \%$, hemicellulose $28 \%$, lignin $20 \%, 4.6 \%$ of other polysaccharides, $3 \%$ of saccharide and $2.4 \%$ of ash, on a dry weight basis [14][15]. Lignucellosuic biomass generally has high carbon contents and less ash as compared to other i.e extracted algae [16]. Bagasse contains carbon (44.1\%), hydrogen $(5.7 \%)$, oxygen $(47.7 \%)$, nitrogen $(0.20 \%)$ and $18.19 \%$ fixed carbon [17]. The yield of ESBSW derived FA was recorded between $24 \%-25 \%$.

The FA with different particle sizes such as 200 and $250 \mu \mathrm{m}$ were then activated and applied as an adsorbent and their performance was evaluated as discussed below.

\section{B. Performance analysis of ESBSW-FA 200}

COD, TS, $\mathrm{pH}$ and turbidity in wastewater were found 800 $\mathrm{mg} / \mathrm{L}, 1.85 \mathrm{mg} / \mathrm{L}, 9.67$ and $200 \mathrm{NTU}$, respectively. Impact of ESBSW-FA 200 treatment mode (10\% and 15\% sulfuric acid) and its bed height on removal efficiency of the pollutant was investigated as shown in Figure 3.

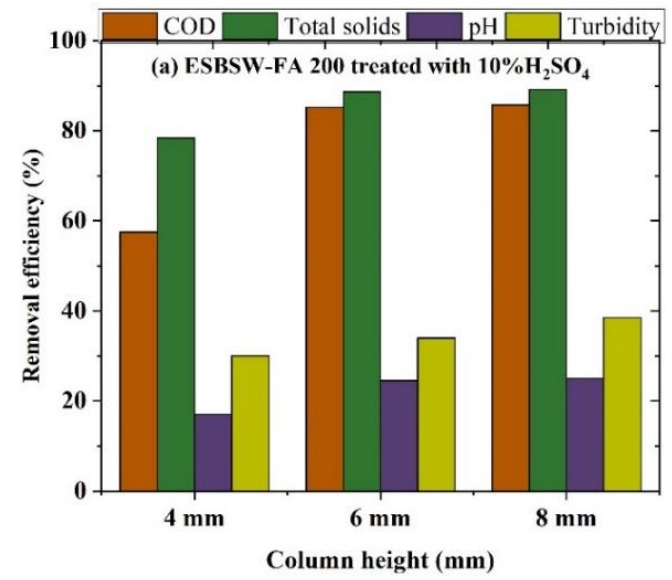

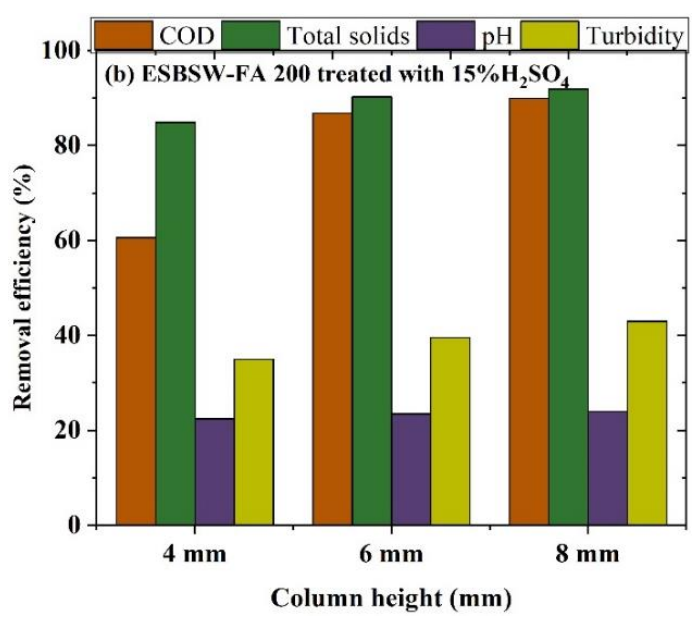

Figure 3 Performance analysis of ESBSW-FA 200 activated with $10 \%$ and $15 \% \mathrm{H}_{2} \mathrm{SO}_{4}$

It could be observed from Figure 3 (a) that COD, TS, pH and Turbidity were reduced by $57.5 \%, 78.37 \%, 17.06 \%$ and $30 \%$, respectively for $4 \mathrm{~mm}$ bed height. Interestingly, the removal efficiency enhanced as the ESBSW-FA 200 bed height was increased from $4-8 \mathrm{~mm}$. The maximum removal efficiency was $85.75 \%, 89.18 \%$ and $38.5 \%$ for COD, TS and turbidity, respectively attained at $8 \mathrm{~mm}$ adsorbent bed height. While $\mathrm{pH}$ was reduced from alkaline to neutral. Wastewater treated by using ESBSW-FA 200 with $15 \%$ acid concentration (Figure 3b) exhibited a similar pathway for pollutant removal with respect to the adsorbent height as for treating with $10 \%$. But the removal efficiency was significantly improved. Maximum removal efficiency for COD, TS and turbidity was $90 \%, 91.8 \%$ and $43 \%$, respectively by using adsorbent treated with $15 \%$ acid. The maximum removal of pollutant at greater adsorbent bed height could be associated with longer interaction duration between adsorbate and adsorbent. Modification of FA with high acid concentration helped to improve the surface features of FA and resulted in high removal efficiency. It has been reported that modification of bone char adsorbent by the suitable method can enhance the surface features of material for high-efficiency removal of pollutant [18].

\section{Performance analysis of ESBSW-FA 250}

Figure 4. presents the impact of ESBSW-FA 250 treatment mode (10\% and $15 \%$ sulfuric acid) and its bed height on the removal efficiency of pollutant. 

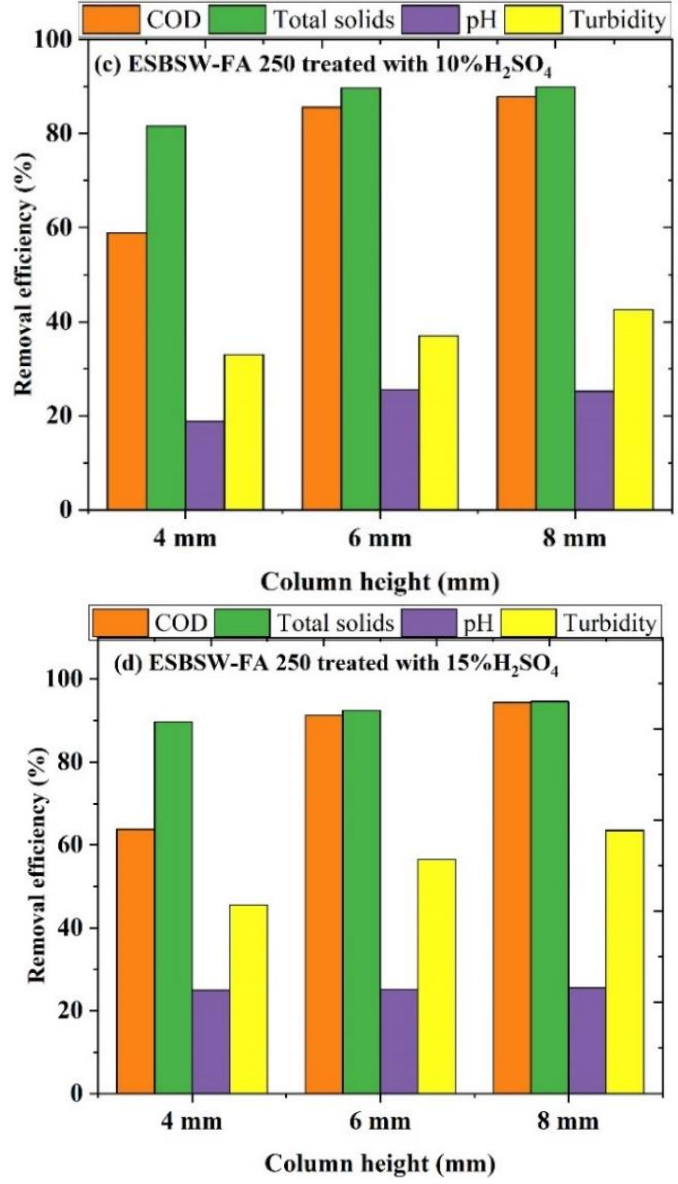

Figure 4 Performance analysis of ESBSW-FA 250 activated with $10 \%$ and $15 \% \mathrm{H}_{2} \mathrm{SO}_{4}$

It could be observed from Figure 4 (a) that COD, TS, $\mathrm{pH}$ and Turbidity were reduced by $58.9 \%, 81.62 \%, 18.82 \%$ and $33 \%$, respectively for $4 \mathrm{~mm}$ bed height. Interestingly, the removal efficiency enhanced as the ESBSW-FA 250 bed height was increased from 4 to $8 \mathrm{~mm}$. The maximum removal efficiency was $88 \%, 90 \%$ and $42.5 \%$ for COD, TS and turbidity, respectively attained at $8 \mathrm{~mm}$ adsorbent bed height. While $\mathrm{pH}$ of treated water was 7.23. Wastewater treated by using ESBSW-FA 250 with $15 \%$ acid concentration (Figure 3b) followed the same fashion for pollutant removal with respect to adsorbent height as for treating with $10 \%$. But pollutant removal efficiency was much higher than the base case. Maximum removal efficiency for COD, TS and turbidity was $94.37 \%$, 95\% and $63.5 \%$, respectively by using adsorbent treated with $15 \%$ acid. The high removal efficiency with increasing bed height is owing to enhanced contact between FA and adsorbate. In addition, rupturing of FA surface by using high concentration of acid during activation process lead to better surface properties and enhanced removal efficiency. Interestingly, the high removal rate with increased particle size could be associated to high available surface area as well.

\section{CONCLUSION AND RECOMMENDATIONS}

Sugarcane bagasse waste derived activated fly ash was employed successfully for the wastewater treatment. Adsorbent particle size, bed height and activation method greatly influenced the removal efficiency of pollutant. ESBSWFA activated with $15 \%$ sulfuric acid with $8 \mathrm{~mm}$ bed height gave maximum removal efficiency for COD, TS, $\mathrm{pH}$ and turbidity. ESBSW after juice extraction is regarded as waste and needs to be handled effectively at large scale processing. FA derived from this waste showed great potential as an adsorbent. Therefore, the recycling of ESBSW for the recovery of valuable products will be economically and environmentally beneficial for industries.

\section{ACKNOWLEDGEMENT}

We are grateful to the Department of Chemical and Engineering, BUITEMS for provision of chemical and equipment's to complete this work.

\section{REFERENCES}

M. I. Ansari and A. Malik, "Biosorption of nickel and cadmium by metal resistant bacterial isolates from agricultural soil irrigated with industrial wastewater," Bioresour. Technol., 2007.

A. K. Shah, Z. M. Ali, A. J. Laghari, S. Farman, A. Shah, and W. Pollutants, "Utilization of Fly Ash as Low-Cost Adsorbent for the Treatment of Industrial Dyes Effluents- A Comparative Study .," J. Eng. Technol., 2013.

P. Saravanakumar, P. Gopalakrishnan, M. Sivakamidevi, and E. S. Archana, "Domestic wastewater treatment using flyash as adsorbent," Int. J. Eng. Adv. Technol., 2019.

M. S. Nawaz and M. Ahsan, "Comparison of physicochemical, advanced oxidation and biological techniques for the textile wastewater treatment," Alexandria Eng. J., 2014.

[5] A. A. Adeyemo, I. O. Adeoye, and O. S. Bello, "Adsorption of dyes using different types of clay: a review," Appl. Water Sci., vol. 7, no. 2, pp. 543-568, 2017.

[6] M. Amin, M. Narayana, Asadullah, S. Kamran sami, M. N. Khan, and S. H. Sultan, "Bioenergy production from waste mango seed shell by thermo-chemical conversion and its importance for mango fruit processing industry," Journal.Buitms.Edu.Pk, vol. 1, no. 09, pp. 48-52, 2019.

[7] X. Sun et al., "Characterization of 60 types of Chinese biomass waste and resultant biochars in terms of their candidacy for soil application," GCB Bioenergy, 2017.

[8] M. Ahmad et al., "Biochar as a sorbent for contaminant management in soil and water: a review.," Chemosphere, 2014.

[9] M. Ali, S. Arifullah, and M. H. Memon, "Edible oil deficit and its impact on food expenditure in Pakistan," in Pakistan Development Review, 2008.

[10] H. Tahir, M. Sultan, N. Akhtar, U. Hameed, and T. Abid, "Application of natural and modified sugar cane bagasse for the removal of dye from aqueous solution," J. Saudi Chem. Soc., 2016.

[11] M. Amin and P. Chetpattananondh, "Enhanced Lipid Recovery from Marine Chlorella $\mathrm{Sp}$. by Ultrasonication with an Integrated Process Approach 
for Wet and Dry Biomass," Bioenergy Res., vol. 12, no. 3, pp. 665-679, Sep. 2019.

[12] M. Amin and P. Chetpattananondh, "Biochar from extracted marine Chlorella sp. residue for high efficiency adsorption with ultrasonication to remove $\mathrm{Cr}(\mathrm{VI}), \mathrm{Zn}(\mathrm{II})$ and $\mathrm{Ni}(\mathrm{II}), "$ Bioresour. Technol., vol. 289, Oct. 2019.

[13] D. Chahal, A. Ahmad, and J. N. Bhatia, "Assessment of agroforestry based two-tier-cropping system in Ambala district of Haryana.," Agric. Updat., 2012.

[14] E. Martinez-Hernandez, M. A. Amezcua-Allieri, J. Sadhukhan, and J. A. Anell, "Sugarcane Bagasse Valorization Strategies for Bioethanol and Energy Production," in Sugarcane - Technology and Research, 2018.

[15] I. Barrera, M. A. Amezcua-Allieri, L. Estupiñan, T. Martínez, and J. Aburto, "Technical and economical evaluation of bioethanol production from lignocellulosic residues in Mexico: Case of sugarcane and blue agave bagasses," Chem. Eng. Res. Des., 2016.

[16] M. Amin and P. Chetpattananondh, "Biochar from extracted marine Chlorella sp. residue for high efficiency adsorption with ultrasonication to remove $\mathrm{Cr}(\mathrm{VI}), \mathrm{Zn}(\mathrm{II})$ and Ni(II)," Bioresour. Technol., vol. 289, 2019.

[17] A. Anukam, S. Mamphweli, P. Reddy, E. Meyer, and O. Okoh, "Pre-processing of sugarcane bagasse for gasification in a downdraft biomass gasifier system: A comprehensive review," Renewable and Sustainable Energy Reviews. 2016.

[18] S. S. A. Alkurdi, R. A. Al-Juboori, J. Bundschuh, and I. Hamawand, "Bone char as a green sorbent for removing health threatening fluoride from drinking water," Environment International. 2019.

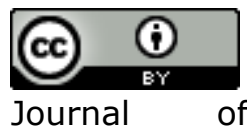
of Applied and Emerging

Sciences by BUITEMS is licensed under a Creative Commons Attribution 4.0 International License. 